\title{
Return to an Old Refrain: What Proof Does to Concepts
}

Ian Hacking, Toronto

Many texts could illustrate my subject. Here is one, almost at random. It is the third and last paragraph in one of the numbered remarks in the Remarks on the Foundations of Mathematics:

One would like to say: the proof changes the grammar of our language, changes our concepts. It makes new connexions, and it creates the concept of these connexions. (It does not establish that they are there; they do not exist until it makes them.) (RFM III, $\left.\S 31^{1}{ }^{1}\right)$

For a tiny bit of context, the previous remark, $\S 30$, ended by saying, 'I want to say that the must corresponds to a track which I lay down in language.'

Why might one want to say these things? I shall suggest one possible reason. I shall couch my answer in terms of what I have read in Wittgenstein, but I am not a scholar aiming at a correct interpretation of his texts.

In addition, although this essay is about proof, I have made the tactical decision, on grounds of brevity, to pass by Wittgenstein's remarks about perspicuous or surveyable proofs. They are of fundamental importance to his philosophical thinking about mathematics. The omission here means most of what follows is in need of qualification in this respect. I also omit his important insistence on the motley of techniques of proof. ${ }^{2}$ (RFM III, § 46, 48.)

${ }^{1}$ Throughout I shall use the translation and numbering of the third edition, Oxford: Blackwell, 1978.

${ }^{2}$ The motley is emphasized in Hacking 2009 and in Hacking 2000. 
First reactions to the publication of Remarks on the Foundations of Mathematics

Passages such as the two just cited were very much discussed, once upon a time, but they have fallen rather by the wayside, overtaken, as it were, by the so-called 'rule-following considerations'. The Remarks were published in 1956, which happens to be the year I went up to Cambridge to read Moral Sciences. As a completely ignorant undergraduate with some prior training in mathematics, I was captivated, and have been so ever since.

Reactions by more mature minds to this posthumous collection of writings were various.

One was Georg Kreisel's, in a review published two years later: 'it seems to me to be a surprisingly insignificant product of a sparkling mind. ${ }^{3}$ It will be recalled that Kreisel attended Wittgenstein's classes on some of the topics of the Remarks, and had deeply impressed him as the rare mathematician who had a philosophical sensibility.

What depressed Kreisel most, was Wittgenstein's discussion of Cantor and the infinite. I shall say not one further word about Wittgenstein and the transfinite.

A different reaction to the publication of $R F M$ was to gnaw away at the suggestion that proofs somehow change, or make more determinate, the concepts that are involved in the theorem proved. Or that a proof provides a new criterion for the use of a concept. Many of Wittgenstein's remarks suggested this idea to his early readers, although often what he wrote was more in the form of an internal dialogue than unqualified assertion. Note the 'One would like to say', and the 'I want to say', of my two opening quotations.

Some philosophers, starting with Alice Ambrose and Michael Dummett, publishing in 1959, took the Remarks very seriously indeed. ${ }^{4}$ Despite the fact that their philosophy, and indeed their lives, had been profoundly influenced by Wittgenstein, these two philosophers were very dubious. One thing that preoccupied them was the suggestion, or group of suggestions, that proof changes concepts by providing new criteria for the application of the concepts involved in the proof. And on reflection, the

\footnotetext{
${ }^{3}$ Kreisel 1958, 158.

4 Ambrose 1959, Dummett 1959.
} 
first generation of readers could not accept it. For brevity I shall speak of the suggestion that proofs modify concepts. Of course Wittgenstein sometimes proposed what may or may not be a different formulation of the same thought, that 'a proof introduces a new concept', by which he says he 'meant something like the proof puts a new paradigm among the paradigms of language'. (III, §31.)

Ambrose argued very clearly and cogently against such suggestions. It is important to contrast, she said, most ordinary proofs, and cases in which a new domain comes into view and there are real choices to be made. For example, the concept number had certainly been 'fixed' or at any rate extended in the course of history. Yes, mathematicians made decisions when they extended the numbers 2, 3, 4 etc., to include 1, and, later, zero. Certainly they did so when they moved on to rational numbers, complex numbers, and real numbers. But in proving, say, that there is no greatest prime number, no decision was made, nor did any new criterion for prime number come into being.

\section{Michael Dummett and the 'ellipse theorem'}

Michael Dummett might have been initially tempted by the suggestion that the proofs modify concepts, but he concluded that it was plain wrong. In 1973 he illustrated his considered position using the fact that a plane intersecting a cylinder forms an ellipse. ${ }^{5}$ Let us call this the ellipse theorem. It is a special case of a quite elementary result in the theory of conic sections.

In what Dummett calls a 'banal' sense of the words, a proof of the theorem provides a new criterion for being a plane intersecting a cylinder. But in no interesting sense does the theorem furnish a new criterion. Nothing we would reject as a cylinder using this criterion would have passed the old, pre-proof criteria for being a cylinder. The 'standard view', Dummett insisted, is that nothing we admit as an ellipse using this criterion would have failed to be an ellipse by the old criteria.

Dummett thinks that the standard view is right, and that if Wittgenstein denied it, he was wrong to do so. More generally, Dummett wrote

${ }^{5}$ Dummett 1978, 300f. 
that: 'Wittgenstein's vision of mathematics cannot be sustained; it was a radically faulty vision.'

To quote him again: 'If Wittgenstein's thesis is to be more than a statement of the obvious, [...]: it must be understood as involving that there are, or may be, plane figures formed by the intersection of a cylinder with a plane which could not have been recognized as ellipses before the proof was given.' And that, Dummett insists, is just false.

The 'thesis' referred to is, in Dummett's words, the proposition 'that a proof induces us to accept a new criterion for the truth of the conclusion'. We may well expostulate, with Peter Hacker in another connection, that Wittgenstein explicitly insisted that he propounded no theses in philosophy. ${ }^{6}$ I shall not harp on that again, and instead will cavil at a more immediate point of English grammar. (Ordinary grammar, not philosophical grammar!)

Dummett wrote that 'there are, or may be, plane figures formed by the intersection of a cylinder with a plane which could not have been recognized.' He should not have written 'are, or may be', but 'might have been' so as to obtain, 'there might have been plane figures formed by the intersection of a cylinder with a plane which would not have been recognized as ellipses before the proof was given.' I have also changed his 'could' to 'would'. Modalities play a significant role in careful exposition of these ideas.

Here I cannot resist a certain childish smugness. I have a proprietary interest in the example. Dummett implies that it comes from Wittgenstein. In fact it comes from the first pages of Hilbert and Cohn-Vossen's Anschauliche Geometrie of 1932, published in English as Geometry and the Imagination. ${ }^{7}$ The book derives from Hilbert's lectures in the winter of 1920-1. Dummett first encountered the example in a talk I gave in Oxford, in 1960, and in a work of mine that he refereed some months later. I used it as an example in my own jejune discussion of these issues to illustrate the 'concept fixing' idea. By 1973, he remembered the example as coming from Wittgenstein himself. No, it did not, but at the time I felt both flat-

\footnotetext{
6 'Soames ascribes theses to Wittgenstein, despite Wittgenstein's explicit insistence that he propounded none', followed by a citation of PI $\$ 128$. In Hacker 2006, 129.

${ }^{7}$ Hilbert / Cohn-Vossen 1952, 6-8.
} 
tered and amused, rather than aggrieved, by the implied attribution. His referee's report was, by the way, negative; he was probably right.

I take the opportunity to note, before proceeding, that there is a consequence of the ellipse theorem that looks as if it could be investigated experimentally. I quote Hilbert and Cohn-Vossen: 'The fact that we have just proved can also be formulated in terms of the theory of projections as follows: The shadow that a circle throws on to an oblique plane is an ellipse, if the light-rays are perpendicular to the plane of the circle.' (p. 8) It is quite common to illustrate the theory of conic sections using shadows. Shine a light at some distance from a sphere, and the shadow cast is an ellipse; shine it very close, and the shadow cast is a parabola.

\section{The debate of the decade}

Many other readers took up the discussion, often expressing a wish to agree with what they took Wittgenstein to be saying, but finding it impossible to do so. To give an idea of the debate, I may mention Chihara (1961, and 1963), Nell (1961), Castaneda (1961), Wood (1961), Levison (1964), Stroud (1965), and Sloman (1968-9). In general, readers of the Remarks before 1970 attended to what they often called a conventionalist strand in Wittgenstein's writing about mathematics. There was the tantalizing assertion that proofs somehow 'fixed' or modified concepts, somehow made them more determinate. One also noticed the importance of proofs being perspicuous or surveyable.

These early reactions and loci of interest were faithful to the published text. The most frequently occurring term in the first edition of the Remarks is not 'rule' but 'proof'. Another key noun is 'application': Anwendung ranks very high in an analytical index. Then we have 'calculation', 'experiment', 'inference', 'measure', and 'picture'. This is not to say that there are no 'rule-following considerations' in the first edition of the Remarks. ${ }^{8}$ But although rules are often mentioned, it is seldom in that context. A more typical statement is: 'The effect of proof is, I believe, that we

${ }^{8}$ In the numeration of the revised edition, we have I- $\S \S 1-3$; I- $\S \S 113-118$; IV- $\S \S 8-9$; VII- $\S 39-40$. I do not mean to imply that these passages do not have application elsewhere in the texts. 
plunge into the new rule' ( $R F M \mathrm{IV}, \S 36$.). This may very naturally be read as a variant on the concept-modification theme, even if it can also be read as about 'rule-following'.

\section{'The rule-following considerations'}

So matters stood throughout the 1970s: Wittgenstein's apparent suggestions fascinated some readers but were taken with much salt. Then there was a great sea-change. Enter the so-called 'rule-following considerations' most famously and brilliantly advanced by Saul Kripke, ${ }^{9}$ but also, quite independently and for different philosophical reasons, by David Bloor. ${ }^{10}$ These considerations were immediately taken up by a whole phalanx of philosophers. No rule determines its own application. Nothing in previous use fixes meanings. I shall take no position on that vast literature. Still, it will influence how you read what I shall say, so for the record: If all positions already held were plotted by some genius on the surface of a globe, I would be somewhere on the continent inhabited by Peter Hacker, and not on the one inhabited by Saul Kripke. Admire, yes. Imitate, no. ${ }^{11}$

Indeed, given that the context of Kripke's reflections was Wittgenstein, it is remarkable that he seemed not to consider application, Anwendung, which will be a critical notion in what follows below. The example used was $68+57=125$. What was the point of adding 68 to $57 ?$ If it is just a calculation in rote arithmetic, there is not much point except in testing a child's skill. But adding is embedded in, indeed embodied in, the world. If you take 68 one euro coins and 57 two euro coins, you have 125 coins in all. Let us be more practical still. The head of a large but very elementary school ensures that classes have exactly 25 members. Last year he had 24 such classes. The school is enlarged to have 25 . He is arranging picnic lunches for the first holiday outing of his pupils. Previously he has never multiplied past 24 times 25. Qultification agrees with multiplication up to 24 times 25 , but 25 times 25 , he says, makes 5 .

${ }^{9}$ Kripke 1982.

${ }^{10}$ Bloor 1983. Bloor continued this theme with for example his 1997.

${ }^{11}$ Or possibly precede. See Hacking 1985. This largely recapitulates some ideas presented in my doctoral dissertation Proof, Cambridge 1962. 
He must be qultifying; he meant quimes when he said 'times' - who is to say (to paraphrase Kripke) that he did not mean quimes all along? Well, if this is just rote arithmetic, who indeed? But the head teacher wants to know the number of school lunches to bring. Last year he multiplied (or qultified, no one cared, then) and brought 200 . This year he is to bring only five? One imagines the pupils and teachers might have something to 'say' about this! It is curious that the enormous literature on Kripke's arguments seldom discusses the uses, the applications, of arithmetic. That would surely have been Wittgenstein's first question? One is tempted to ask why clever people did not think it would be clever to say: 'don't ask for the meaning of 'plus', ask for its uses.' Uses in the ordinary sense of the word, however: thus one of the uses of multiplication is to work out the number of school lunches to bring. ${ }^{12}$

I shall leave that worry to one side. The rule-following considerations are entirely general; quusification must work for the ellipse theorem. It may or may not be significant that ellipses are not as easy as for 'quus'. I think it is significant, because with ellipses we are so readily drawn to conic sections, and hence to real-life material projections of light and shadow, as mentioned by Hilbert himself.

Evidently it must, however, be possible to quusify 'ellipse' just as you can quusify 'plus'. (Note that it is easier to gruify 'ellipse' than to quusify it. ${ }^{13}$ ) You might try this. You (or rather a pseudo-Apollonius in late antiquity) have been doing only plane geometry. You turn to three dimensions. Consider the concept of an ellapse (with two $l$ s) which applies to ellipses in two dimensions and, in three, to circles inscribed on planes. There is nothing in the history of usage to determine that the noun 'ellipse' does not refer to ellapses. When pseudo-Apollonius turns to the cylinder and considers it intersected by a plane, he infers that if the plane is orthogonal to the cylinder, the curve of intersection is an ellapse, but otherwise not.

${ }^{12}$ These observations parallel, in a different key, Mary Hesse's (1969). In her terminology, working out the number of school lunches is one of the ramifications of arithmetic.

${ }^{13}$ It is seldom noticed that Goodman and Kripke mesh less well together than is sometimes thought. See Hacking 1993. 
Let us suppose that such an imagined sequence of events is logically possible.

It is certainly not much more possible than that: the rule following considerations inhabit the space of logical possibility, not real human possibility. ${ }^{14}$ Of course there are real contingencies of meaning, such as I recently illustrated with Putnam's example of 'jade', ${ }^{15}$ with the example of 'measles', or long ago with the case of the rule for a draw in chess, an example that I took from J. E. Littlewood. ${ }^{16}$ A game is drawn if the same position recurs three times. What if the same spatial position recurs three times, but with black's rooks interchanged? Does the rule mean same spatial position, or same historical position? This ambiguity is not just logically possible. According to Littlewood, it actually arose in an important match in 1924. But the rule following considerations are not like that, they are not about possibilities, but about logical possibilities.

How would the logical possibility that 'ellipse' meant 'ellapse' as just defined, bear on Dummett's concern, rewritten by me as, whether 'there might have been plane figures formed by the intersection of a cylinder with a plane which would not have been recognized as ellipses before the proof was given.' At best, it would be something like this: It might have been the case that plane figures formed by the intersection were not recognized as ellipses, because when people first transferred 2-D notions to $3-\mathrm{D}$, they carried on using the word 'ellipse' to mean 'ellapse'. But although this is not irrelevant, I believe it quite literally changes Dummett's topic of conversation. Dummett's concerns altogether preceded the rule following considerations, and to introduce them here is a red herring. They enter at a different stage in the argument, as we shall briefly see below.

${ }^{14}$ Kripke does not put things in this way, with good reason preferring to contrast normative and descriptive accounts of dispositions to speak in certain ways. See: Kripke 1982, 37.

15 Hacking 2007.

${ }^{16}$ Cf. Bloor 1983. The example goes back to my reading, about 1960, of J. E. Littlewood's charming A Mathematician's Miscellany, London: Methuen, 1953. 


\section{Logical positivism reduced to absurdity}

One of my favourite pair of sentences in the history of analytic philosophy is from Ayer's Language, Truth and Logic: '[O]ur knowledge that every oculist is an eye doctor depends on the fact that the symbol "eye-doctor" is synonymous with "oculist." And the same holds good for every other $a$ priori truth. ${ }^{17}$ This is the reduction to absurdity of the rather sophisticated idea circulating in Vienna, that necessary truth and propositions known $a$ priori are true by convention, conventions about the meaning of the words. Among the innumerable virtues of Ayer's absurdity is that the noun 'oculist' was used in 1936 British English - that is, when Ayer first published his magnificent polemic - to mean what is now called, in Britain and elsewhere, an ophthalmologist. So it is a real example of a word not maintaining its meaning. But the same holds good for every other a priori truth ?!!!

We can also play the quus game with the word 'oculist', calling in question the claim that prior conventional synonymy suffices to explain, or perhaps even legitimate, the status of Ayer's exemplar proposition as a necessary truth. Doubtless it can be argued that the quus game confutes the entire doctrine of truth by convention. But of course that had already been done in the year that Ayer came back from Vienna and published Language, Truth and Logic. For 1936 was also the year that Quine published 'Truth by Convention'. ${ }^{18}$ His was not the last word in a debate among the logical positivists and their heirs, but I find it just as compelling today as I did the morning I read as an undergraduate. That in no way implies that I feel compelled by a next move, the denial of the distinction between the analytic and the synthetic. More than one thoughtful and knowledgeable philosopher has said to me that 'Truth by Convention' was Quine's best paper.

There is little doubt that the doctrine of truth by convention came into being when members of the Vienna Circle were forming an acquaintance with the Tractatus and indeed with Wittgenstein himself. How much of the doctrine did they think they took from that book? How much did they think they took from the man himself? Those are questions best left to scholars. Many readers, including the judicious Scott Soames, appear to

\footnotetext{
17 Ayer 1946, 85 .

${ }^{18}$ Quine 1936.
} 
believe that Wittgenstein held, or at any rate was strongly attracted to, some version of the doctrine of truth by convention throughout his life. I have encountered no evidence for that belief.

\section{Pure mathematics ${ }^{19}$}

Ayer reminds us of what the doctrine of truth by convention was all about: necessary truth and a priori knowledge. It is also about Kant's first question: How is pure mathematics possible? Whatever Kant meant, the definitive $20^{\text {th }}$ century gloss on Kant is due to Bertrand Russell, 1912. 'The question which Kant put at the beginning of his philosophy, namely "How is pure mathematics possible?" is an interesting and difficult one, to which every philosophy which is not purely sceptical must find some answer'. ${ }^{20}$ Why, in Russell's opinion, must all philosophers find an answer? Because: 'The apparent power of anticipating facts about things of which we have no experience is certainly surprising. ${ }^{21}$

Note that Russell's worry is about the a priori, not necessity. Kant asked about apodictic certainty rather than logical necessity. Necessity, in my opinion, arises from scholastic philosophy, often expressed as a concern about what were called eternal truths. In the high Middle Ages the problematic was usually different from ours. The schoolmen focussed on the question whether God could make the eternal truths different from what they in fact are.

There is a tradition in analytic philosophy of mathematics of regarding necessity and the a priori as one of the two central problem areas. ${ }^{22}$ The second area is trying to understand profound new results, with which we rightly associate the names of Cantor and Gödel. Allow me an aside that may be pertinent.

19 The material in this and the next section is developed at much greater length in Hacking 2009. References will be found in that paper.

${ }^{20}$ Russell 1946, 84. Kant's question is stated in Kant 1929, 56 (B 20).

${ }^{21}$ Russell 1946, 85.

${ }^{22}$ To repeat, if the axes of traditional problematization of mathematics are (a) the a priori and (b) necessity, then (a) is Kantian, while (b) is mediaeval. This is a subtext, I suppose, of my 1973 lecture, 'Proof and Eternal Truths', reprinted in Hacking 2002. 
Consult the Stanford and the Routledge encyclopedias of philosophy. Early in the Routledge, we read that,

During the nineteenth and twentieth centuries, however, the most influential ideas [in the philosophy of mathematics] have been those of Kant. In one way or another and to a greater or lesser extent, the main currents of foundational thinking during this period - the most active and fertile period in the entire history of the subject - are nearly all attempts to reconcile Kant's foundational ideas with various later developments in mathematics and logic. ${ }^{23}$

Kant does not even occur in the Stanford article on the philosophy of mathematics. Necessity and the a priori hardly surface. That is not to say they are not elegantly and informatively discussed. But not under mathematics, philosophy of.

The difference between Stanford and Routledge depends on fairly recent events and emphases. There is something both less and also more local in the question of why $20^{\text {th }}$ century analytic philosophy was obsessed by necessity and a priori knowledge.

The less local is this: From the time of Galileo to the nineteenth century, mathematics was primarily what we call applied mathematics. Geometry, we all know, was Plato's idol. Newton dismissed it as merely practical, an aide to architects.

Mathematics, in his opinion, was rational mechanics, the use of mathematical reasoning to understand the nature of God's handiwork. He was not rejecting geometry as applied, but as superficial, as not investigating nature deeply enough.

Leave out God, sometimes, and these are the views of Lagrange, Legendre, and Laplace. Of Euler and Gauss. In Newton's Cambridge, virtually every young man who won the coveted annual Smith's Prize in mathematics won it for distinction in what we would call applied mathematics - I am thinking of host of famous names from 1768 onwards, names such as John Herschel, G. B. Airy, G. G. Stokes, William Thomson (Lord Kelvin), P. G. Tait, and the greatest physicist of the $19^{\text {th }}$ century, James Clerk Maxwell. Physicists all, but in the terminology of their education, mathematicians.

\footnotetext{
${ }^{23}$ Detlefsen 1998, 181.
} 
Neither Plato's questions about geometry, which lead on to the philosophical problems of the a priori, nor the mediaeval questions about the necessity of mathematics, interested Newton or subsequent cohorts of men who thought of themselves as mathematicians and Natural Philosophers. Those questions simply did not arise. Their prevalence in some twentieth century schools of mathematics is a result of history, not of mathematics, that is, a history that made pure mathematics seem to dominate the field. I suggest that philosophical interest in the a priori is the result of wholly contingent developments in the development of what was called mathematics.

Although Francis Bacon had distinguished pure and mixed mathematics, as he called it, mathematicians did not much bother with the distinction, except that it was used to make a place for probability theory. Where could one stash that, whether in its guise as the doctrine of chances or as the art of conjecturing? Answer: as mixed mathematics. But historically, probability and statistics has wandered all over the tree of knowledge. For instance, once it was the prime example of mixed and not pure mathematics, but Cambridge University has for some time had a Department of Pure Mathematics and Mathematical Statistics, as opposed to Applied Mathematics and Theoretical Physics.

The philosophers from Bacon to d'Alembert and on to Kant liked the distinction between pure and mixed, but it became institutionalized among mathematicians only in 1810 with Gergonne's Annales de mathématiques pures et appliqués, confirmed in 1826 with Crelle's Journal für die reine und angewandte Mathematik. If you think that necessity and the $a$ priori are core issues in the philosophy of mathematics, you are an heir of Kant, and the Routledge Encyclopedia is right on the mark. It was Kant who directed subsequent philosophers to pure mathematics, which is not to say that he meant by that label what we do.

\section{Wittgenstein, mathematics, and Cambridge}

Wittgenstein was trained as an aeronautical engineer, a science that we classify, perhaps, as applied mathematics. When he came to Cambridge, he entered a world where pure mathematics was king. As I have just said, it had not always been so, not at all. Only in 1863 was the Sadleirian Chair of 
Pure Mathematics created. But by the time Wittgenstein arrived at Russell's door, pure mathematics reigned, in the form of G. H. Hardy, who caused pure mathematics to be the dominant kinds of maths at the University, the applied mathematics being designated Natural Philosophy, physics, and/or applied mathematics. Because his predecessor Hobson was longlived, and did not retire until he reached the age of 75, Hardy did not assume the Sadleirian Chair until 1931, but he was the man almost from the time he took up a lectureship in 1906. Alongside Hardy there was Littlewood, elected fellow of Trinity in 1908, and actually elected to a chair before Hardy. Hardy always had his eye on the Sadleierian chair. And then there was Whitehead: 'The science of Pure Mathematics, in its modern developments, may claim to be the most original creation of the human spirit. $^{, 24}$

You may well think this did not impinge on Wittgenstein, but of course it did, and not only via Russell. For an explicit contact, consider the discussions much later, in the 1939 lectures edited by Cora Diamond. It is well known that they begin by mentioning a remark of Hardy's. Look, however, at the discussion of the construction with ruler and compass of the heptacaidecagon, the name he uses for a 17 sided regular polygon, or 17-gon as I shall call it. ${ }^{25}$ He moves on to the constructability of the pentagon and non-constructibility of a heptagon (5-gon and 7-gon respectively). Why should this have come up?

Because Hardy and Wright's Introduction to The Theory of Numbers had just been published in 1938. It contains an elegant new proof of the fact first proved by Gauss, namely the constructability of the 17-gon. (Hardy and Wright called it a heptacaidecagon, which is the name that Wittgenstein used, although it is only one of several possible names for the figure.) Locally, in Cambridge, the proof was regarded as one of the triumphs of the book, and it was the talk of the town.

\footnotetext{
${ }^{24}$ Whitehead 1925, 28.

${ }^{25}$ Wittgenstein 1976, 77.
} 


\section{Applied mathematics, von Mises, and Vienna}

I've been making it sound as if Wittgenstein's life as a philosopher of mathematics was moulded in Cambridge. But he was Viennese! I owe to Friedrich Stadler the realization that there was a great debate about pure and applied mathematics even within the Vienna circle. The chief protagonist was Richard von Mises (not to be confused with his brother Ludwig, the economist). Von Mises is now best known to philosophers for his frequency theory of probability, a thorough work of, among other things, logical positivism.

Von Mises strongly identified himself as an applied mathematician, and regularly insisted, against some other members of the Vienna circle, that mathematics could be properly understood only by its applications. His dissertation was on the determination of flywheel masses in crank drives. You may fancy a connection with Wittgenstein's example of flywheel diagrams. ${ }^{26} \mathrm{He}$ was also an aeronautical engineer, giving the first university lecture course ever, anywhere, on powered aircraft in Strasbourg, 1913, and himself becoming a test pilot during the Great War, and designing the Mises-Flugzeug, a 600 HP flying machine that was too late for development into a fighter plane.

Immediately after the war von Mises became head of the new Institute of Applied Mathematics in Berlin, and in 1921 he founded the Zeitschrift für Angewandte Mathematik und Mechanik. ${ }^{27}$ Although most of the Vienna circle were 'Russellian' and thought of mathematics in terms of pure mathematics, the residual effect of von Mises was strong, and, I would guess, really influential on a thinker of Wittgenstein's stripe. In a fanciful mood I would suggest that it may be helpful to look at the man stereoscopically, with one lens focused on Vienna, and the other on Cambridge. Through the Vienna eye he sees application, thorough the Cambridge eye, he sees purity.

Wittgenstein became fascinated by the Kantian problems when he went as a young man to Cambridge, and acquired the philosophical problematic of pure mathematics, that is, of Russell and Whitehead and of turn-

\footnotetext{
${ }^{26}$ Eg. RFM IV §21; VII §72. Also Wittgenstein 1976, 195.

27 See Siegmund-Schultze 2004.
} 
of-the-century Cambridge as a whole. But he retained his applied instincts, reinforced, I suggest, by von Mises.

\section{The by-product theory of tautology, logic, and mathematics}

The Tractatus has a definitive resolution of traditional difficulties. The sentences of logic are tautologies. My positivistic way of putting an insight, that one can derive from the Tractatus, is that tautologies are by-products of notation. ${ }^{28}$ If you have the notation for truth functions, for constructing complex sentences out of atomic ones, you will thereby generate extreme points, complex sentences that say nothing. How are necessary truths possible? In the case of tautology, they are falsely assimilated to truth. But if truths say something about the world, then tautologies are not truths. They are degenerate.

But that will not quite do. Notations are optional, we choose them by convention. That may appeal to logical positivism but not to Wittgenstein. It is tempting to give a transcendental status to tautology. The very possibility of stating more than atomic propositions brings degeneracy in its wake.

The situation for mathematics appears similar if, as Wittgenstein seems to say, the propositions of mathematics are identities. Identity was a matter on which Ramsey and Wittgenstein strongly disagreed, and I am not sure that their disagreement was resolved to the satisfaction of either. Wittgenstein entered a long period of wandering: I will for the nonce follow the views that James Conant has stated at this very conference: I think of the so-called second Wittgenstein as operating after Norway, 1937. That is when most of the new thoughts and worries about mathematics began to be written down. $^{29}$

We can entertain a residual idea of the 'by-product' type. We should not think of some truths as contingent and others as necessary, as if logical necessity were an eternal property of some but not all truths. The feeling of necessity should be thought of as a by-product - of what we do

\footnotetext{
28 The metaphor of by-products was first used in Hacking 1979.

${ }^{29}$ Of course old ones persist. $R F M$ III $\$ 33$ (iii): 'But what about $p \supset p$ ? I see in it a degenerate proposition, which is on the side of truth.'
} 
with certain sentences. Wittgenstein hardly ever used the philosophers' terminology of logical necessity. ${ }^{30}$ But we can suggest one of his thoughts using our tired jargon. We come to treat a proposition as logical necessary, to use it as necessary, only when it is proven.

But was it not always true, true all along? Very likely, although as Imre Lakatos's Proofs and Refutations has taught us, don't be so sure that counterexamples do not lurk. ${ }^{31}$ The property of logical necessity, however, is acquired only with proof and use.

Surely the very meanings of the words, and the criteria for their use, settle that the proposition was not only true all along, but also necessarily true? This is where the rule-following considerations may be invoked, in this reconsideration of what we might learn from reading Wittgenstein.

The notorious 'hardness of the logical must' is there - but only when we have made a proof. It is the dust stirred up by this conviction, this must, that creates philosophical confusion. The philosophical theorizing is prompted less by proof than by the dust which it stirs up. ${ }^{32}$

The proof convinces us of something - though what interests us is, not the mental state of conviction, but the applications attaching to this conviction.

For this reason, the assertion that the proof convinces us of the truth of this proposition leaves us cold, - since this expression is capable of the most various constructions. (RFM III, §25.)

From this point of view we may return to the starting point of our opening quotation. At some points in his internal monologue Wittgenstein wanted to say that a proof 'makes new connexions, and it creates the concept of these connexions. (It does not establish that they are there; they do not exist until it makes them.)' And: 'I want to say that the must corresponds to a track which I lay down in language.'

${ }^{30} \mathrm{He}$ did mention it in scare quotes, as in $R F M \mathrm{~V} \S 41$ : 'Concepts which occur in "necessary" propositions must also occur and have a meaning in non-necessary ones.' This is importantly connected to Wittgenstein's emphasis on the applications of mathematics.

${ }^{31}$ Lakatos 1970. I showed in Hacking 2000, $\S$ 7-8, that Lakatos and Wittgenstein complement each other more than one would expect, or, indeed, more than either of them would have liked.

32 This is, perhaps, a one-sentence summary of Hacking 2000. 
The laying down in language is not a choice, in the sense of a deliberate, free-will sort of choice. It is an event in the experience of proof. Dummett's idea of self-conscious, explicit, conventionalism is highly misleading as a representation of Wittgenstein's chain of reflection.

Wittgenstein goes in for a full-blooded conventionalism; for him the logical necessity of any statement is always the direct expression of a linguistic convention. That a given statement is necessary consists always in our having expressly decided to treat that very statement as unassailable. ${ }^{33}$

No, we do not decide. Yes, there is a line in the dialogue, a question: 'Why should I not say: in the proof I have won through to a decision?' (RFM III, $\S 27$.) Let us attend less to the question than to the assertion: 'The effect of proof is, I believe, that we plunge into a new rule.' (RFM IV, §36.) Plunge - what a wonderful choice of words! $!^{34}$ Necessity is the by-product of a track that we lay down in language: So much is a residue of the Tractatus. But, pace passages in the dialogue that contemplate the contrary, we do not literally decide to lay down the track. To mix the metaphors, we plunge into a new rule, bringing a new sense of necessity with it.

Internal relations - necessary connections - come into being in the course of proof. We make no self-conscious decision. And we think of them as necessary only when there is the picture of application in the background. That is the core of the a priori. As Russell put it in 1912, 'The apparent power of anticipating facts about things of which we have no experience.'

Return to the ellipse theorem. Might there have been (to repeat my rephrasing of the question Dummett regarded as critical) plane figures formed by the intersection of a cylinder with a plane which would not have been recognized as ellipses before the proof was given? As a matter of fact, rather than of Kripkian rule-following logical possibility, no. But this does not mean that the 'track had been laid down in language' with what we philosophers call logical necessity. If we wish to use the jargon, that happened only after the proof, and in conjunction with the idea of an application of the theorem.

\footnotetext{
33 Dummett 1978a, 170.

34 „Der Effekt des Beweises sei, so meine ich, dass der Mensch sich in die neue Regel hineinstürzt.“ (One may question whether the sei is correctly translated as 'is'.)
} 
Dummett was right to assert that (in all probability) nothing we admit as an ellipse using the criterion provided by the ellipse theorem would have failed to be an ellipse by the old criteria. We could put it this way: nothing is a criterion until it is used as a criterion. And the ellipse theorem is used as a criterion only when it is proven. That way of putting things is obviously grossly simplistic. It may however suggest that what Dummett called the trivial sense of being a new criterion has its deeper side, and is one of those things so obvious that we do not notice it.

All this ties in well with the idea that a proof is a picture of an experiment. This is yet another thought expressed in the dialogue form of, in this case, 'might say'. 'Thus I might say: the proof does not serve as an experiment; but it does serve as the picture of an experiment.' (RFM I, $\S 36$.) We saw that David Hilbert himself drew attention to the way in which the proof of the ellipse theorem can be illustrated by an experiment (or what looks like an experiment!): 'The fact that we have just proved can also be formulated in terms of the theory of projections: The shadow that a circle throws on to an oblique plane is an ellipse, if the light-rays are perpendicular to the plane of the circle.'

Now take this seriously as an experiment. How would we go about determining that the shape of shadow cast on the plane really is an ellipse? What measurements would we take, in real experimental life? You can tell just by looking, but if someone insisted that it is not quite an ellipse, what to do next? In truth no one would care, but if we imagine some crackpot being sceptical, then, if the proof is to hand, it overrides experiment. And if it is not to hand, well, the sceptic may well be allowed to ramble on, for no real-life measurements are going to bear on the question.

If we stop thinking about necessity as an abstract and timeless property of propositions, and see it as something connected with application, then the thought that 'proofs fix concepts' (and the litany of related thoughts) no longer appears paradoxical. The first readers of Wittgenstein were on to something of great importance to traditional (Kantian!) philosophy of mathematics, but they were not able to overcome their scholastic conception of necessity as deriving from eternity - eternal truths - rather than from use. ${ }^{35}$

${ }^{35}$ For an earlier way of coming at these issues, see Hacking 2002a. 


\section{Literature}

Ambrose, Alice 1959: 'Proof and the Theorem Proved'. Mind 68, 435-445.

Ayer, A. J. 1946: Language, Truth and Logic. $2^{\text {nd }}$ Edition. London: Gollancz.

Bloor, David 1983: Wittgenstein: A Social Theory of Knowledge. London: Macmillan.

Bloor, David 1997: Wittgenstein, Rules and Institutions. London: Routledge.

Castaneda, Hector-Neri 1961: 'On Mathematical Proofs and Meaning'. Mind 70, 385390.

Chihara, Charles 1961: 'Wittgenstein and Logical Compulsion'. Analysis 21, 136-140.

Chihara, Charles 1963: 'Mathematical Discovery and Concept Formation'. Philosophical Review 72, 17-34.

Detlefsen, Michael 1998: 'Mathematics, Foundations of'. In Craig, E. (ed.): Routledge Encyclopedia of Philosophy, vol. 6. London / New York: Routledge, 181-92.

Dummett, Michael 1959: 'Wittgenstein's Philosophy of Mathematics'. Philosophical Review 68, 324-348, reprinted in 1978: Truth and Other Enigmas. London: Duckworth, 166-185.

Dummett, Michael 1978: 'The Justification of Deduction'. In: Truth and Other Enigmas. London: Duckworth, 290-318.

Dummett, Michael 1978a: 'Wittgenstein's Philosophy of Mathematics'. In: Truth and Other Enigmas. London: Duckworth, 166-185.

Hacker, Peter 2006: 'Soames's History of Analytic Philosophy'. Philosophical Quarterly 56, 121-131.

Hacking, Ian 1979: 'What is Logic?' Journal of Philosophy 76, 285-319.

Hacking, Ian 1985: 'Rules, Scepticism, Proof, Wittgenstein'. In: Hacking, Ian (ed.) Exercises in Analysis: Essays by Students of Casimir Lewy. Cambridge: Cambridge University Press, 113-124.

Hacking, Ian 1993: 'On Kripke's and Goodman's Uses of "Grue”. Philosophy 68, 269-295.

Hacking, Ian 2000: 'What mathematics has done to some and only some philosophers'. In Smiley, T. J. (ed.): Mathematics and Necessity. London: British Academy, 83-138.

Hacking, Ian 2002: 'Proof and Eternal Truths'. In: Historical Ontology. Cambridge, MA: Harvard University Press, 200-213.

Hacking, Ian 2002a: 'Les preuves et la nécessité chez Wittgenstein'. In: Bouveresse, J. / Laugier, S. / Rosat, Jean-Jacques (eds.): Dernière Wittgenstein, Dernières Pensées. Marseille: Agone, 265-288. 
Hacking, Ian 2007: 'The Contingencies of Ambiguity'. Analysis 67, 269-277.

Hacking, Ian 2009: 'What Makes Mathematics Mathematics?' In: Lear, Jonathan / Oliver, Alex (eds.) The Force of Argument: Essays in Honour of Timothy Smiley. London: Routledge, 82-106.

Hesse, Mary 1969: "Ramifications of "Grue". British Journal for the Philosophy of Science 20, 13-25.

Hilbert, David / Cohn-Vossen, Stephan (1952): Geometry and the Imagination, translated by P. Nemenyi. New York: Chelsea.

Kant, Immanuel 1929: The Critique of Pure Reason, translated by Norman Kemp Smith. London: Macmillan.

Kreisel, Georg 1958: 'Wittgenstein's Remarks on the Foundations of Mathematics'. British Journal for the Philosophy of Science 9, 135-158.

Kripke, Saul 1982: Wittgenstein on Rules and Private Language. Cambridge, MA: Harvard University Press.

Lakatos, Imre 1970: Proofs and Refutations. Cambridge: Cambridge University Press.

Levison, A. B. 1964: 'Wittgenstein and Logical Laws'. Philosophical Quarterly 14, 345-354.

Levison, A. B. 1964a: 'Wittgenstein and Logical Necessity'. Inquiry 7, 367-373.

Nell, E. J. 1961, "The Hardness of the Logical "Must"”. Analysis 21, 68-72.

Littlewood J. E. 1953: A Mathematician's Miscellany. London: Methuen.

Quine, W. v. O. 1936: 'Truth by Convention'. In: Lee, Otis H. (ed.): Philosophical Essays for A. N. Whitehead. New York: Longman's, Green \& Co. Reprinted in 1966: The Ways of Paradox. New York: Random House, 70-99.

Russell, Bertrand 1946: The Problems of Philosophy. London: London: Oxford University Press.

Siegmund-Schultze, Reinhard 2004: 'A Non-conformist Longing for Unity in the Fractures of Modernity: Towards a Scientific Biography of Richard von Mises'. Science in Context 17, 333-370.

Sloman, Aaron 1968-9: 'Explaining Logical Necessity'. Proceedings of the Aristotelian Society 69, 35-50.

Stroud, Barry 1965: 'Wittgenstein and Logical Necessity'. Philosophical Review 74, 504-518.

Whitehead, A. N. 1925: 'Mathematics as an Element in the History of Thought'. In: Science and the Modern World: Lowell Lectures 1925. New York: Macmillan, 28-54. 
Wittgenstein, Ludwig 1976: Wittgenstein's Lectures on the foundations of mathematics, Cambridge, 1939: from the notes of R. G. Bosanquet, Norman Malcolm, Rush Rhees, and Yorick Smythies, edited by Cora Diamond. Ithaca, NY: Cornell University Press.

Wittgenstein, Ludwig 1978: Remarks on the Foundation of Mathematics. $3^{\text {rd }}$ Edition. Oxford: Blackwell. (RFM)

Wood, O. P. 1961: 'On Being Forced to a Conclusion'. Proceedings of the Aristotelian Society, Supplementary Volume 35, 15-44. 
